\title{
Applying Regression Discontinuity Design to Social Policy: An Evaluation of the Welfare-to-Work Program in South Korea
}

\author{
Seog-Min Lee* and Huck-ju Kwon**
}

\begin{abstract}
Social policy studies focusing on poverty reduction attempt to measure poverty reductions rates and poverty gaps, but they do not provide criteria to determine whether a given social policy is a success or failure. In this study, we suggest using regression discontinuity design to establish evaluation criteria and validate estimation results in social programs. Using the dataset from the Korean Welfare Panel, first we conduct, first, a difference-in-differences comparison between welfare recipients under the National Basic Livelihood Security system and nonrecipients whose income falls under the minimum cost of living. Secondly, we establish the counterfactual effects of the program among nonrecipients whose income is below the minimum cost of living and among nonrecipients whose income is above the minimum cost of living. Last, we analyze treatment effects by comparing welfare recipients with income below the minimum cost of living and nonrecipients with income above the minimum cost of living using the regression distribution design method. We argue that the National Basic Livelihood Security system as a welfare-to-work program has positive effects on labor market participation, which has not been established by previous studies.
\end{abstract}

Keywords: regression discontinuity design, welfare-to-work programs, working days, labor income

\section{INTRODUCTION}

A large body of research in social policy that focuses on poverty reduction and labor supply attempts to measure reduction of poverty rates and increases in income

\footnotetext{
* Seog-Min Lee is an associate professor in the Department of Public Administration at the University of Suwon, Korea. E-mail: newmind68@suwon.ac.kr.

** Huck-ju Kwon is a professor in the Graduate School of Public Administration and the deputy director of the Asia Development Institute at Seoul National University, Korea. E-mail: hkwon4@snu.ac.kr.
}

Manuscript received October 21, 2015; out for review November 15, 2015; review completed February 5, 2016; accepted March 25, 2016.

The Korean Journal of Policy Studies, Vol. 31, No. 1 (2016), pp. 1-29.

(C) 2016 by the GSPA, Seoul National University 
after welfare policy implementation in order to evaluate performance (Bavier, 2001; Cancian, Haveman, Meyer, \& Wolfe, 2002; Ellwood, 2000; Grogger, 2003; Gruber, 2000; Meyer \& Rosenbaum, 2000; Page \& Stevens, 2005; Schoeni \& Blank, 2000). For this purpose, most international studies calculate the mean ratio of change in the level of poverty in recipient groups or measure the mean difference between welfare recipients and nonrecipients using econometrics or quasi-experiment methods (e.g., difference in differences [DID], propensity score matching [PSM], and fixed effects).

These studies provide important information for policy evaluation. However, they do not provide criteria for determining policy success or failure. In other words, they do not provide a way to assess whether poverty reduction and income increases among welfare recipients or whether whatever the mean difference between recipient and nonrecipient groups is means a policy is successful or not. In addition, the methods estimate the average effect before and after treatment, which disregards the difference in prior characteristics of recipients and nonrecipients.

This study suggests the use of regression discontinuity design (RDD) to establish evaluation criteria and validate estimation results. We analyze the welfare-to-work program in South Korea (Korea hereafter) using RDD. One of the main purposes of welfare-to-work reform programs in many countries is to help recipients participate in the labor market and ultimately enable them to support themselves; in turn, it is hoped that governments will be able to reduce expenditure on social welfare. These welfareto-work programs, implemented worldwide from the 1990s, have generated substantial research analyzing their effects, about which there is no consensus.

The remainder of this paper is organized as follows. The next section discusses RDD and explains why RDD is relevant to social policy evaluation. Thereafter, we review current worldwide trends in social policy evaluation and the characteristics of the National Basic Livelihood Security (NBLS) system as a welfare-to-work program in Korea and outline the research method. Then, we review the results and limits of PSM-based DID and the usefulness of the information RDD provides. The last section summarizes findings and provides conclusions.

\section{REGRESSION DISCONTINUITY DESIGN APPROACH}

\section{Basic Assumptions}

If $Y_{i}(1)$ is the outcome of participant $i$ in the welfare program, and $Y_{i}(0)$ is the outcome of non-participant $i$, then $Y_{i}(1)-Y_{i}(0)$ is the average treatment effect (ATE). However, we cannot observe $Y_{i}(0)$, or the potential outcomes to be estimated (Imbens 
\& Rubin, 2007), making it very difficult to obtain the ATE. The best way to solve this endogeneity problem is to compare a treatment group with a control group, both of which are assigned randomly. Many methods are used to address endogeneity: DID, PSM, instrumental variables, and quantile regression as a quasi-experiment (Angrist \& Pischke, 2008).

$\mathrm{RDD}$ is regarded as a more precise method than other natural experiments from the viewpoint of estimation validity, although it has low applicability because it requires a known assignment variable (Black, Galdo, \& Smith, 2005; Shadish, Galindo, Wong, Steiner, \& Cook, 2011). RDD has been adopted when the treatment and control groups are not randomly assigned owing to probable systematic differences and when the selection rule for how samples are assigned to each group is known explicitly. RDD can be modeled through a regression equation between the outcome and assignment variables and consists of sharp regression discontinuity (SRDD) and fuzzy regression discontinuity (FRDD). ${ }^{1}$

In SRDD, the individuals just below the cutoff point are allocated to the treatment group, and those over the cutoff point to the control group, or vice versa. According to Imbens and Lemieux (2008), SRDD assumes, first, that assignment occurs through a known and measured deterministic decision rule, which has a positive density in a neighborhood of the cutoff point. Second, it assumes that the probability of assignment jumps from zero to one at the cutoff point. Moreover, the assignment and outcome variables should not have a correlation indicating endogeneity. In general, strong ignorability conditions (Rosenbaum \& Rubin, 1983) — unconfoundedness and overlapare needed to remove endogeneity. RDD violates the overlap condition because there is no common support for matching. This generates excessive extrapolation; to avoid this, a third assumption - local continuity - is that conditional expectations are continuous only at the cutoff point. Equation 1 shows the ATE of subjects close to the cutoff point, that is, the difference of average outcomes or two regression functions at a cutoff point.

$$
\lim _{x \downarrow c} E\left(y_{i} \mid x\right)-{ }_{x{ }^{\prime} c}^{\lim } E\left(y_{i} \mid x\right)=\left[{ }_{x \downarrow c}^{\lim } E\left(\beta_{i} t_{i} \mid x\right)+{ }_{x \downarrow c}^{\lim } E\left(\mu_{i} \mid x\right)\right]-\left[{ }_{x \uparrow_{c}}^{\lim } E\left(\beta_{i} t_{i} \mid x\right)+{ }_{x \uparrow_{c}}^{\lim } E\left(\mu_{i} \mid x\right)\right]=E\left(\beta_{i} \mid c\right)
$$

1. Thistlethwaite \& Campbell (1960) introduced RDD as an alternative method for evaluating social programs; Angrist \& Lavy (1999), Goldberger (2008), and Van der Klaauw (2002) have developed the approach; Hahn, Todd, \& Van der Klaauw (2001) have formalized it; and Imbens \& Kalyanaraman (2012) have strengthened its estimation ability and have applied it to many different research areas. 
Meanwhile, FRDD is assigned stochastically, that is, with a propensity score function. For example, if the probability of assignment is discontinuous from 0.4 to 0.8 at the cutoff point, SRDD ranges from 0 to 1 . FRDD requires that discontinuity of the treatment variable and local continuity of the assignment variable at the cutoff point are known. In addition, treatment effects are independent of treatment variables or occur irrespective of whether individuals are allocated to treatment or control groups. Thus, ATE in FRDD indicates the local ATE (LATE) as shown in equation 2. The denominator is the change in probability of treatment at the cutoff point and is always nonzero because of known discontinuity of $E(t \mid x)$ at $x$, whereas, in sharp RDD, the denominator just equals one.

$$
\frac{\lim _{x \downarrow_{c}} E\left(y_{i} \mid x\right)-{ }_{x \uparrow_{c}}^{\lim _{c}} E\left(y_{i} \mid x\right)}{\lim _{x \downarrow_{c}} E\left(t_{i} \mid x\right)-{ }_{x \uparrow_{c}}^{\lim _{c}} E\left(t_{i} \mid x\right)}
$$

Both SRDD and FRDD are estimated using parametric and nonparametric methods. With the parametric method, we are able to find an optimal function model between outcome and assignment variables to fit a given dataset, whereas the nonparametric method allows us to select an optimal data range within which to produce a simple local linear regression.

\section{Estimation Method}

The parametric equation function for this study is determined according to Trochim (1984) and Wong, Cook, Barnett, and Jung (2008). As the regression functional form is not known, we have overfitted the model with polynomial and interaction termslinear, linear interaction, quadratic, quadratic interaction, cubic, and cubic interaction, from highest to lowest order- to examine the statistical significance of each model.

$$
\begin{aligned}
& y_{i}=\delta D_{i}+f\left(x_{i}\right)+\varepsilon_{i} \\
& y_{i}=\alpha+\delta D_{i}+\beta_{1} x_{i}+\beta_{2} x_{i}^{2}+\beta_{3} x_{i}^{3}+\gamma_{1} D_{i} x_{i}+\gamma_{2} D_{i} x_{i}^{2}+\gamma_{3} x_{i}^{3}+\varepsilon_{i}
\end{aligned}
$$

In equation $3, Y_{i}$ is the outcome measure for observation $i$, and $f\left(x_{i}\right)$ is a smooth nonlinear and $p^{\text {th }}$-order polynomial function of the continuous assignment variable, or the control function - augmented outcome equation (Heckman \& Robb, 1985). $D_{i}$ is a dichotomous indicator variable, such that $D_{i}=1$ for observations assigned to the treatment group; otherwise $D_{i}=0$. The coefficient $\delta$ for treatment assignment represents the marginal impact of the program at the cutoff point. $\varepsilon_{i}$ is a random error term for 
observation $i$, and $\alpha$ is the average value of the outcome for those in the treatment group. Equation 4 allows us to obtain more precise estimates of the treatment effect, but the results must not differ largely from those of equation 3.

$$
Y_{i}=\alpha+\delta D_{i}+f\left(x_{i}\right)+m\left(\gamma_{i}\right)+\varepsilon_{i}
$$

where $f\left(x_{i}\right)$ is a smooth function of the continuous assignment variable, including polynomials and interaction terms, and $m\left(\gamma_{i}\right)$ is a vector of covariates' characteristics.

There are various methods for nonparametric estimation; her we use a rectangular kernel estimator and local linear regression (local polynomial regression or lowess) (see Angrist \& Pischke, 2008, and Hahn \& Van der Klaauw, 2001). This study finds that the estimates of the rectangular kernel estimator are the same as or similar to those of local linear regression.

In general, selection of bandwidth in nonparametric estimation requires finding a balance between precision and bias. Using a broader bandwidth is likely to yield more precision effects because such a method entails using more data for regression, but it also leads to bias; using a narrower bandwidth, by contrast, produces less precise effects but also less bias. Ways to choose optimal bandwidth include a cross-validation

procedure proposed by Imbens and Lemieux (2008) and Ludwig and Miller (2007) and a plug-in procedure developed by Fan and Gijbels (1996) in the context of local linear regressions. Both methods are founded on the concept of minimizing mean square error and investigating the trade-off between bias and precision in the various models. This study uses the plug-in method.

The subjects in our samples had varying prior characteristics, meaning heterogeneity between recipients and nonrecipients in terms of covariates, which increases when samples are far from the cutoff. Therefore, we needed to use both parametric and then nonparametric methods, which many researchers (Angrist \& Pischke, 2008; Imbens \& Lemieux, 2008; Shadish et al., 2011) recommend doing, although the need for it depends on the context of study. This study first examines the validity of welfare program effects in subsamples and subsequently focuses on all samples, in line with the NBLS program's theory and evaluation criteria.

\section{RDD for Social Policy Evaluation}

In vocational training programs, the experimental and comparative groups can be matched easily by PSM, and the performance difference between two groups can be estimated by DID to determine whether the policy has succeeded or failed. However, the characteristics of recipients of welfare programs differ substantially from those of 
nonrecipients. Therefore, it is generally accepted that if a welfare program has a clear cutoff point for selection, especially two assigned groups that are difficult to match because they do not possess the same characteristics, then RDD is a more suitable methodological approach than PSM or DID, which require common and equivalent characteristics between treatment and control groups (Imbens \& Lemieux, 2008; Shadish et al., 2011; Thistlethwaite \& Campbell, 1960). RDD is a way of estimating treatment effects in a quasi-experimental setting in which treatment is determined by a known cutoff point (a fixed threshold) on an observed assignment variable (Lemieux \& Milligan, 2008).

In figure 1, social policy RDD locates recipients in the left area and nonrecipients in the right area. The intercept difference at the cutoff point (e.g., minimum cost of living [MCL]) between two groups is the criterion for evaluating program success. This is more rational than using the poverty gap or DID, both of which consider average differences between two groups to evaluate policy success. It would be difficult for the average income of the group of recipients to equal or exceed that of the group of nonrecipients because the two groups have, for example, different levels of education and different labor skills. If the policy is successful, the treatment group regression line in figure 1 closes in on long-term effects, that is, the slope of the regression line becomes horizontal. Finally, if the two groups under evaluation are systematically different and

Figure 1. RDD for Social Policy

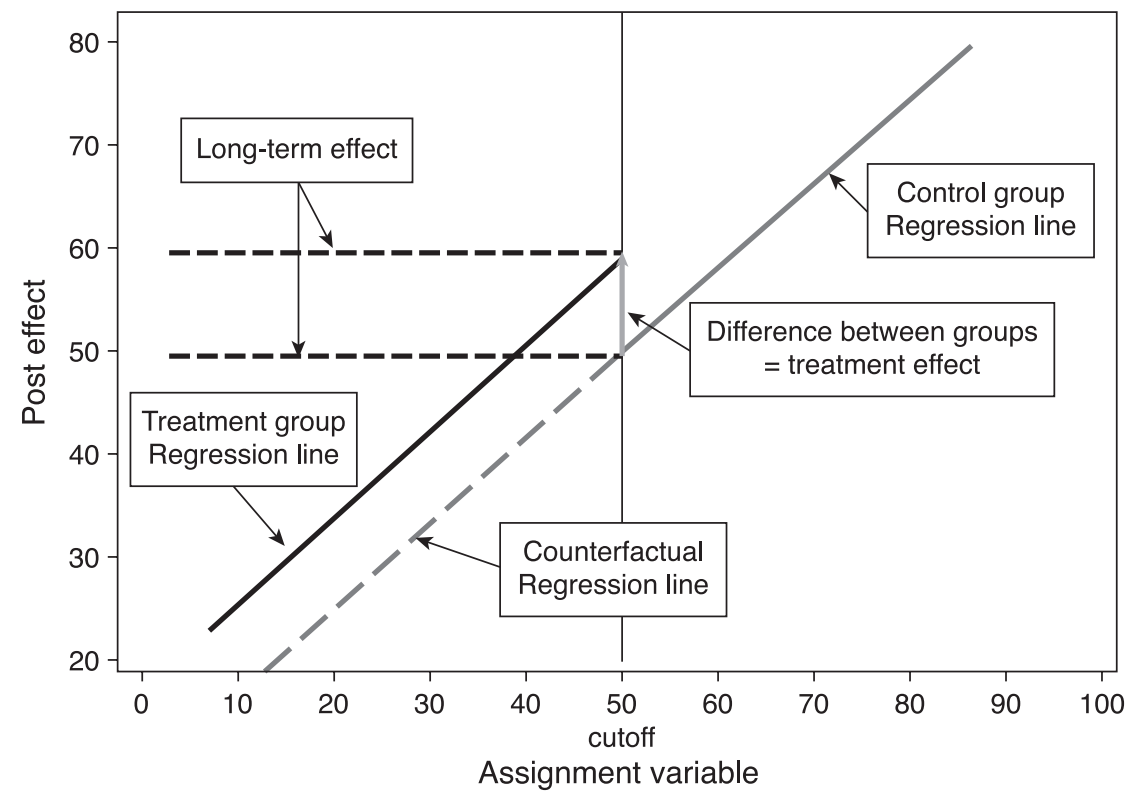

The Korean Journal of Policy Studies 
there are ambiguous criteria for evaluating outcomes, RDD can be a good alternative method to address these issues. Meanwhile, the counterfactual regression line indicates potential outcomes that could be observed without welfare recipiency.

However, although RDD is a more precise method, it is difficult to apply owing to prerequisite conditions that are difficult to meet, especially in social policy. Although it is easy to find an assignment variable from the data of recipients, it is very difficult to draw an exact assignment variable from the data of nonrecipients, which is necessary to apply RDD. Hence, little statistical analysis of social policy has been conducted via RDD in the United States, Europe, and elsewhere. ${ }^{2}$

\section{REVIEW OF SOCIAL POLICY EVALUATION: WELFARE-TO-WORK PROGRAM}

\section{Effects of Social Assistance on Labor Supply}

Much research on welfare-to-work programs has focused on the their labor market effects because if welfare recipients earn incomes, they receive reduced welfare pay in the next year, which might prevent them from participating in the labor market (Rosen, 2004). Studies provide differing conclusions on this subject.

In the case of the United States, the Personal Responsibility and Work Opportunity Reconciliation Act of 1996, a landmark in American social policy, replaced Aid to Families with Dependent Children with Temporary Assistance for Needy Families. The new benefit sanctions recipients who do not comply with requirements and its criteria for eligibility have reduced the number of nonworking recipients who are able to receive benefits. Gilbert (2009) shows that working hours and economic activity rates of welfare recipients who do move into work increase, although a substantial majority of them earn wages below the poverty line and remain in unstable employment. In addition, Waddan (2003) finds that the majority of welfare recipients who participate in the labor market remain in poverty.

However, Danziger, Heflin, Corcoran, Oltmans, and Wang (2002), using panel data and a fixed-effects model, conclude that since welfare reform was effected in the United States, working mothers have had higher household incomes and lower poverty rates,

2. Lemieux and Milligan (2008) employ RDD to evaluate the incentive effects of transfer programs by comparing recipients under the age of 30 years without children and recipients older than 30 years who receive $40 \%$ more benefits than the former group. However, the study does not compare recipients with nonrecipients. 
and that they also report that working mothers have had less difficulty living on their current incomes. Other researchers (Bavier, 2001; Cancian et al., 2002) find modest financial gains among welfare recipients who became wage reliant after welfare reform. Bloom, Hill, and Riccio (2003) look at data gathered from multisite experiments of mandatory welfare-to-work programs conducted over a 15-year period and find that welfare-to-work programs can be effective for many different client types in the United States. Cheng's (2010) analysis shows that the majority (57\%) of the working poor who received welfare benefits transitioned to working nonpoor status.

Canada launched a health and social transfer system in 1995 that built on principles of compulsory participation and financial sanctions for nonparticipation. Lightman, Mitchell, and Herd (2010) use longitudinal microdata files from 1996 to 2001 to assess the impact of this program and find that recipients earn lower wages, work fewer hours, and consequently, have lower annual earnings. On the other hand, Canada also conducts a government-run Self-Sufficiency Project Plus, which offers a range of services, such as an employment plan, a resume service, job clubs, job coaching, job leads, and various workshops. Schwartz and Zabel (2008), using PSM, show that this program helps to achieve a significantly higher full-time employment rate.

The United Kingdom's adoption of welfare reform in 2008 suggests that the income support program to push single parents into the labor market was unsuccessful for a substantial proportion of single parents targeted by policy reform (Rafferty \& Wiggan, 2011). However, ever since 2008, when single parents began receiving a jobseeker's allowance instead of income support their economic activity has increased. Some estimates suggest that single parent welfare-to-work rates increased by around four percentage points between 2007 and 2011 as a result of the jobseeker's allowance (Whitworth, 2013).

In Norway, an emphasis on welfare-to-work policies resulted in the 2003 launch of a comprehensive action plan to combat poverty. Using PSM, Rønsen and Skarðhamar (2009) find there is no impact on immigrants and single mothers while for youth, the effect may even be negative. The only significant effect in a positive direction is found in employment entry rates among long-term social assistance recipients.

\section{Welfare Work Program and Effect Evaluation in Korea}

Korea has implemented its own social program to promote the transition from receiving welfare to entering the workforce. Specifically, in 2000, Korea launched the NBLS system, which is the most important component of the country's social assistance. NBLS is premised on two significant principles. First, it should provide all people earning less than the MCL with income support, housing benefits, self-reliance 
assistance, health benefits, and educational benefits in order to help them maintain a basic standard of living, which means offering general and tied assistance. ${ }^{3}$ Second, NBLS requires recipients to participate in the labor market and provides incentives for them to do so. The intention is to break the cycle of poverty and thus decrease government expenditure. This is the welfare-to-work program that this study focuses on.

Applicants for NBLS must meet two requirements. First, they have to be without family members who can support them. East Asian countries tend to emphasize family obligations, and Korea and Japan have strictly enforced this requirement. Second, their amount of accepted income (AAI) from the previous year must be less than the MCL. The government announces the MCL annually after deliberation by the Central Committee for Livelihood Security (Ministry of Health and Welfare, 2001). The Ministry of Health and Welfare assesses the previous year's AAI by investigating those households that have applied for NBLS and then determining a payment amount that represents the difference between the AAI and MCL. Moreover, the AAI comprises assessed income and income that derives from converting assets to cash, which are rigorously tracked, especially car and housing costs. Hence, the Korean model is unique compared to those of other countries.

Following the international research trend, much research has been conducted on the extent to which NBLS has encouraged recipients to participate in the workforce to reduce their poverty levels. The conclusions of many of the studies that have examined the effectiveness of welfare-to-work programs so far have been mixed, similar to the results of studies of these programs in other countries. There are two directly opposing studies regarding the impact of NBLS on labor supply. First, Kim (2008) finds that the activity rate and number of working days of recipients decrease by $0.56 \%$ and 1.6 hours, respectively, but are statistically insignificant, which means that NBLS does not necessarily have negative effects on labor supply. Park and Kim (2011) demonstrate that nonrecipients outstrip recipients in activity rate, employment rate, number of working days, and labor income; these results are generally believe to be more accurate than Kim's (2008). Both studies use matched double difference using DID and PSM.

Finally, international studies on welfare-to-work programs that include Korea in their scope have used econometrics or quasi-experiment methods to measure the rate of change rate in earnings, activity, or the number of days worked among members of

3. General assistance provides cash benefits for all or most people below a specified minimum income level, whereas categorical assistance provides cash benefits for specific groups. Tied assistance includes free or subsidized access to specific goods or services, either in kind or in cash (see Eardley, Bradshaw, Ditch, \& Gough, 1996). Temporary Assistance for Needy Families is a form of categorical and tied assistance. 
the recipient group and the mean difference between the recipient and nonrecipient groups. However, as noted, these methods are not relevant for the evaluation of social policy. In the next section, we explore the possibility of using RDD to assess social policy.

\section{RESEARCH METHOD}

\section{Research Framework}

Figure 2 shows the flow of our research. Before evaluation, the AAI of between one and five households was determined and applied as an assignment variable. First, in $<1>$, we used PSM-based DID to match recipient households to nonrecipient households with income under the MCL in order to find the difference in two groups with respect to the number of days worked and labor income earned. We then compared this DID result to RDD results. Second, we used RDD to compare group (A) nonrecipients with income under the MCL, with group (B, nonrecipients with income above the MCL, in order to find out the counterfactual effect of NBLS. Last, we used RDD to compare both group (C) Recipients with income under the MCL, and group (D) nonrecipients with income above the MCL, in order to find the treatment effect of NBLS. Our

Figure 2. Research Framework

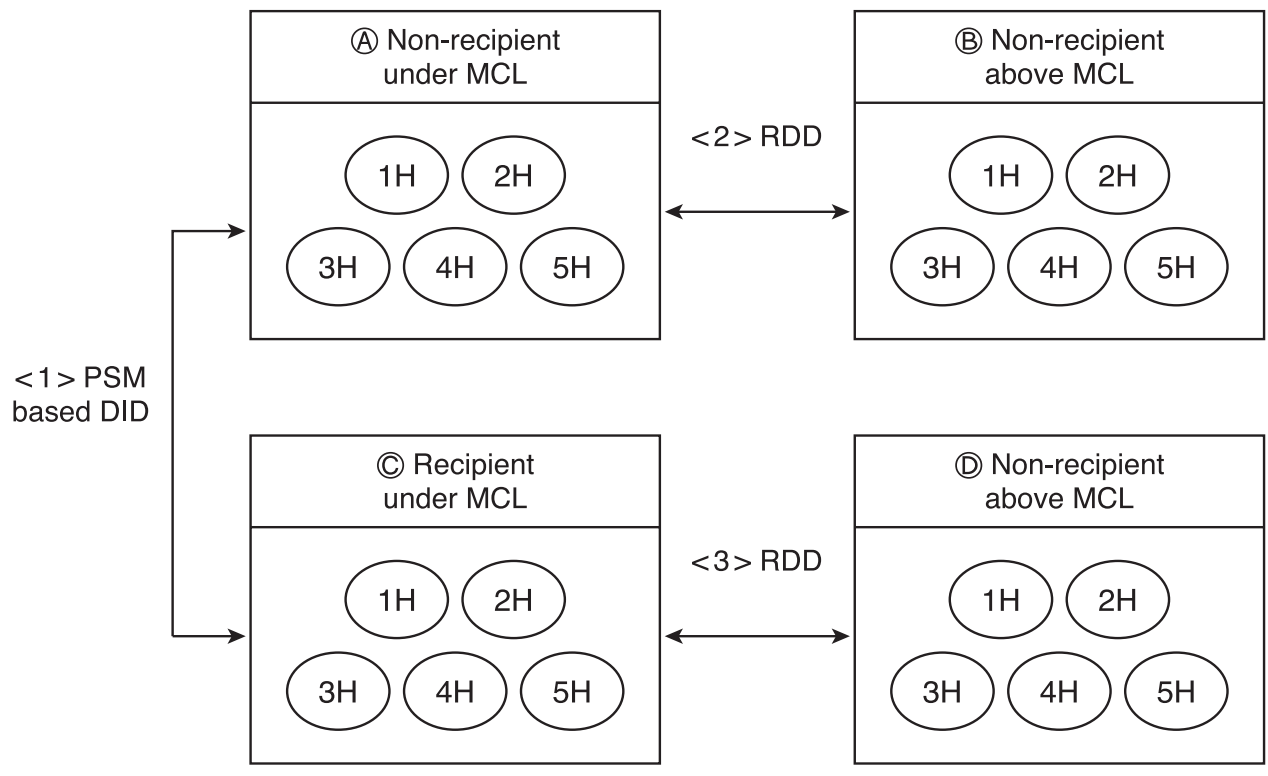


assessment of the information provided by each estimation leads us to conclude that NBLS has been effective in helping welfare recipients become part of the labor force.

\section{Datasets}

This study uses the Korean Welfare Panel Study (KWPS), a longitudinal study on 7,071 households that has been ongoing since 2005. This comprehensive dataset provides information on pertaining to social needs of families and individuals, patterns of resource use, economic and demographic data, income sources, and health status. Data for this study are taken from the seventh (2011) and eighth (2012) waves. The AAI, an assignment variable, is based on 2011 data, while the number of days worked and labor income earned, dependent variables, are based on 2012 data. From these panel data, this study produces three datasets (see table 1). The dataset for the DID analysis is composed of recipients and nonrecipients with income under the MCL. ${ }^{4}$ The dataset for the first RDD analysis is composed of nonrecipients with income under the MLC and nonrecipients with income above the MCL. Last, the dataset for the second RDD analysis comprises recipients with income under the MCL and nonrecipients with income above the MCL.

Households in parentheses in table 1 are families that are used to verify the results of each estimation. ${ }^{5}$ For example, the DID results we arrived at using the first subdataset $(721: 1,227)$ are compared with those of the second subdataset in parentheses (212:337), which is a part of the first subdataset. The second subdataset is expected to show the precise policy effects; however, if two results are similar, this study reports those of the first subdataset.

The AAI, number of days worked, and labor income earned as dependent variables are equivalized with the help of an equivalence scale. We use household size and age of members as the determinants in order to analyze households with different compositions. Some of the most commonly used scales include the OECD equivalence scale (also called the Oxford scale), the OECD modified scale, and the square root scale. This study adopts the square root scale, which recent OECD publications use for comparing

4. There are nonrecipients who cannot qualify for aid mainly because they have family members who ostensibly could support them or because they or own assets, such as houses or cars. However, if these nonrecipients do not receive assistance from their family members or generate income from assets. they remain under the MCL.

5. There is distribution bias in the KWPS panel in low-income households owing to a declining original sample size, which induces a biased representation of the population. In order to correct the bias, KWPS created new samples of households in 2011. 
Table 1. Dataset Composition

\begin{tabular}{|c|c|c|c|c|c|c|c|}
\hline Household Size & $1 \mathrm{H}$ & $2 \mathrm{H}$ & $3 \mathrm{H}$ & $4 \mathrm{H}$ & $5 \mathrm{H}$ & Total & $\begin{array}{l}\text { Evaluation } \\
\text { Method }\end{array}$ \\
\hline $\begin{array}{l}\text { Recipients with Income } \\
\text { under the MCL }\end{array}$ & $\begin{array}{c}342 \\
(116)\end{array}$ & $\begin{array}{l}192 \\
(53)\end{array}$ & $\begin{array}{l}110 \\
(26)\end{array}$ & $\begin{array}{c}45 \\
(12)\end{array}$ & $\begin{array}{l}32 \\
(5)\end{array}$ & $\begin{array}{l}721 \\
(212)\end{array}$ & \multirow{2}{*}{ DID } \\
\hline $\begin{array}{l}\text { Nonrecipients with Income } \\
\text { under the MCL }\end{array}$ & $\begin{array}{c}658 \\
(169)\end{array}$ & $\begin{array}{c}435 \\
(136)\end{array}$ & $\begin{array}{c}79 \\
(21)\end{array}$ & $\begin{array}{l}37 \\
(9)\end{array}$ & $\begin{array}{l}18 \\
(2)\end{array}$ & $\begin{array}{l}1,227 \\
(337)\end{array}$ & \\
\hline $\begin{array}{l}\text { Nonrecipients with Income } \\
\text { under the MCL }\end{array}$ & $\begin{array}{c}658 \\
(169)\end{array}$ & $\begin{array}{c}435 \\
(136)\end{array}$ & $\begin{array}{c}79 \\
(21)\end{array}$ & $\begin{array}{l}37 \\
(9)\end{array}$ & $\begin{array}{l}18 \\
(2)\end{array}$ & $\begin{array}{l}1,227 \\
(337)\end{array}$ & \multirow{2}{*}{ First RDD } \\
\hline $\begin{array}{l}\text { Nonrecipients with Income } \\
\text { above the MCL }\end{array}$ & $\begin{array}{c}335 \\
(128)\end{array}$ & $\begin{array}{c}544 \\
(191)\end{array}$ & $\begin{array}{l}177 \\
(52)\end{array}$ & $\begin{array}{l}213 \\
(47)\end{array}$ & $\begin{array}{l}85 \\
(18)\end{array}$ & $\begin{array}{l}1,354 \\
(436)\end{array}$ & \\
\hline $\begin{array}{l}\text { Recipients with Income } \\
\text { under the MCL }\end{array}$ & $\begin{array}{c}342 \\
(116)\end{array}$ & $\begin{array}{l}192 \\
(53)\end{array}$ & $\begin{array}{l}110 \\
(26)\end{array}$ & $\begin{array}{c}45 \\
(12)\end{array}$ & $\begin{array}{l}32 \\
(5)\end{array}$ & $\begin{array}{c}721 \\
(212)\end{array}$ & \multirow{2}{*}{$\begin{array}{l}\text { Second } \\
\text { RDD }\end{array}$} \\
\hline $\begin{array}{l}\text { Nonrecipients with Income } \\
\text { above the MCL }\end{array}$ & $\begin{array}{c}335 \\
(128)\end{array}$ & $\begin{array}{c}544 \\
(191)\end{array}$ & $\begin{array}{l}177 \\
(52)\end{array}$ & $\begin{array}{l}213 \\
(47)\end{array}$ & $\begin{array}{l}85 \\
(18)\end{array}$ & $\begin{array}{l}1,354 \\
(436)\end{array}$ & \\
\hline
\end{tabular}

${ }^{*}$ New households generated in the data are in parentheses.

income inequality and poverty (OECD, 2008, 2011). ${ }^{6}$ Last, a cutoff point is necessary to carry out an RDD analysis. This study pooled the equivalized the AAI of five households and determined the cutoff point via high scores $(\$ 615$ for the first subdataset and $\$ 590$ for the second subdataset, given in parentheses in table 1).

The panel data have an equivalized AAI variable only for recipients; thus, we should determine that of nonrecipients with income under the MCL and those with income above the MCL in the data using the same calculation method that the government uses when determining the AAI of applicants for NBLS. This study calculates the AAI of recipient households independently of the existing AAI. The correlation between the AAI given by the data and the AAI calculated by this study is 0.70 , which is statistically significant. The real AAI of nonrecipients with income under the MCL and of recipients with income above the MCL are unknown, and so we had to calculate it. While we cannot estimate how close the real AAI is to the calculated AAI of nonrecipients, it can be assumed to be similar to 0.70 for nonrecipients with income under the MCL and far more than 0.70 for nonrecipients with income above the MCL. This is because the manual used to investigate the eligibility of applicants is complex and detailed for low-income earners but relatively simple for those earning more than the

6. The estimation results using other equivalence scales are similar to those of the square root scale. See Atkinson, Rainwater, and Smeeding (1995) for a detailed explanation of the equivalence scale. 
MCL. Last, this study uses the given real AAI of recipients. To supplement the incompleteness of the AAI of nonrecipients, this study uses larger samples of nonrecipients than of recipients. In addition, as already noted, we also use a rectangular (uniform) kernel function for the nonparametric estimation, whereas other researchers commonly use triangle kernel or local linear regression (see Guo and Fraser, 2010).

\section{Model}

Equation 4 is the semiparametric model used for this study. The dependent variables $\left(Y_{i}\right)$ are the number of working days and labor income in the eighth (2012) wave of the KWPS. The number of working days is measured by multiplying the number of months an individual engaged in the labor market by monthly average working days. Labor income refers to regular or irregular payments, business income, and second-job income. The assignment variable $\left(x_{i}\right)$ is an AAI from the seventh (2011) wave. In order to prevent multicollinearity, we differenced the cutoff point ( $x_{c}=615$ and 590) using the original AAIs, thereby generating modified AAIs. In $\delta D_{i}, \delta$ is the treatment indicator; this study designates the experiment group as $\mathrm{D}=1$ and the control group as $\mathrm{D}=0$.

$$
\begin{aligned}
Y_{i}= & \alpha+\delta D_{i}+\beta_{1}\left(x_{i}-x_{c}\right)+\beta_{2}\left(x_{i}-x_{c}\right)^{2}+\beta_{3}\left(x_{i}-x_{c}\right)^{3}+\gamma_{1} D_{i}\left(x_{i}-x_{c}\right)+ \\
& \gamma_{2} D_{i}\left(x_{i}-x_{c}\right)^{2}+\gamma_{3}\left(x_{i}-x_{c}\right)^{3}+f(x)+\varepsilon_{i}
\end{aligned}
$$

This study uses covariates for PSM matching and $f(x)$ in equation 5. The covariates are $\operatorname{sex}(0=$ male, $1=$ female $)$, age, labor ability $(1=$ impossibility of labor, $2=$ only household chores and earning in house, 3 = possibility of labor), education of a householder (number of years in school), number of household members employed, region ( 1 = big city, $2=$ medium and small city, $3=$ rural $)$, job $(1=$ regular, $2=$ irregular, $3=$ unemployed), asset income, private transfer income, and public transfer income.

\section{Results and Discussion}

\section{DID Analysis}

We conducted a DID evaluation in order to compare the results with those of an RDD analysis. Prior to undertaking the DID evaluation, we used PSM to match covariates of the recipient and nonrecipient groups in first subdataset. Table 2 shows that pseudo $R^{2}$, which is the systemic difference between two groups after matching, is 0.003 , which we interpret as very low. The total propensity score is 0.48 , which means 
Table 2. Propensity Score Matching (First Subdataset)

\begin{tabular}{l|c|c|c|c}
\hline \multirow{2}{*}{ Variable } & \multicolumn{2}{|c|}{ Mean } & \multicolumn{2}{c}{ t-test } \\
\cline { 2 - 5 } & $\begin{array}{c}\text { Recipients } \\
\text { with Income } \\
\text { under the MCL } \\
(\mathrm{D}=1)\end{array}$ & $\begin{array}{c}\text { Nonrecipients } \\
\text { with Income } \\
\text { under the MCL } \\
(\mathrm{D}=0)\end{array}$ & $\mathrm{t}$ & $\mathrm{p}>\mathrm{t}$ \\
\hline Age (in Years) & 63.31 & 63.02 & 0.532 & 0.59 \\
\hline Female (\%) & 0.57 & 0.56 & 0.23 & 0.82 \\
\hline Education (in Years) & 7.04 & 7.25 & -1.25 & 0.21 \\
\hline Labor Ability (Weak) & 0.48 & 0.46 & 0.94 & 0.35 \\
\hline Labor Ability (Strong) & 0.49 & 0.51 & -1.23 & 0.22 \\
\hline Number of Family Members & 1.27 & 1.29 & -1.26 & 0.15 \\
\hline Number of Household & 0.31 & 0.33 & -1.07 & 0.28 \\
\hline Members employed & 0.30 & 0.32 & -0.80 & 0.42 \\
\hline Region (City) & 0.18 & 0.16 & 1.89 & 0.06 \\
\hline Region (Rural) & 0.15 & 0.18 & -2.52 & 0.01 \\
\hline Job (Irregularly Employed) & 0.06 & 0.06 & 0.47 & 0.64 \\
\hline Job (Self-Employed) & 0.78 & 0.75 & 2.012 & 0.04 \\
\hline Job (Unemployed) & 0.48 & 0.48 & .02 & 0.99 \\
\hline Propensity Score & & & & \\
\hline Pseudo R (Distbution of & & & & \\
\hline
\end{tabular}

Pseudo $\mathrm{R}^{2}$ (Distribution of Bias): 0.003

that the two matched groups are very similar. ${ }^{7}$

Table 3 reports the results of the DID we conducted on the two subdatasets, which indicates that nonrecipients with income under the MCL statistically outstrip recipients with income under the MCL in terms of the number of days worked and labor income earned. As can be seen in figure 3, the labor income of recipients in 2011 (25.44) is similar to that in 2012 (25.41), and the distribution does not vary. However, the labor income (25.4) of nonrecipients with income under the MCL in 2011 increased by 34.9 in 2012 . The change of distribution indicates that extremely or severely poor households earn more labor income for a living.

These results could be interpreted as indicating the failure of the welfare-to-work program to induce recipients to participate in the labor force. However, comparing

7. PSM with the second subdataset produced similar results, which are not reported in this paper. 
Table 3. Difference-in-Differences Matching Estimation

\begin{tabular}{l|l|c|c|c|c|c}
\hline \multicolumn{1}{c|}{ Dataset } & Variable & $\begin{array}{c}\text { Recipients } \\
\text { with Income } \\
\text { under the MCL }\end{array}$ & $\begin{array}{c}\text { Nonrecipients } \\
\text { with Income } \\
\text { under the MCL }\end{array}$ & Difference & S.E. & T-stat. \\
\hline $\begin{array}{l}\text { First } \\
\text { Subdataset }\end{array}$ & $\begin{array}{l}\text { number of } \\
\text { working days }\end{array}$ & -2.90 & 17.31 & -20.21 & 4.34 & $-4.65^{\star}$ \\
\cline { 2 - 8 } & labor income & -0.61 & 10.98 & -11.60 & 1.69 & $-6.87^{\star}$ \\
\hline $\begin{array}{l}\text { Second } \\
\text { Subdataset }\end{array}$ & $\begin{array}{l}\text { number of } \\
\text { working days }\end{array}$ & -.23 & .96 & -1.19 & .57 & $-2.10^{*}$ \\
\cline { 2 - 8 } & labor income & -.03 & 10.72 & -10.74 & 2.84 & $-3.79^{*}$ \\
\hline
\end{tabular}

${ }^{*}$ Significant at $5 \%$

Figure 3. Distribution of Labor Income (Second Subdataset)

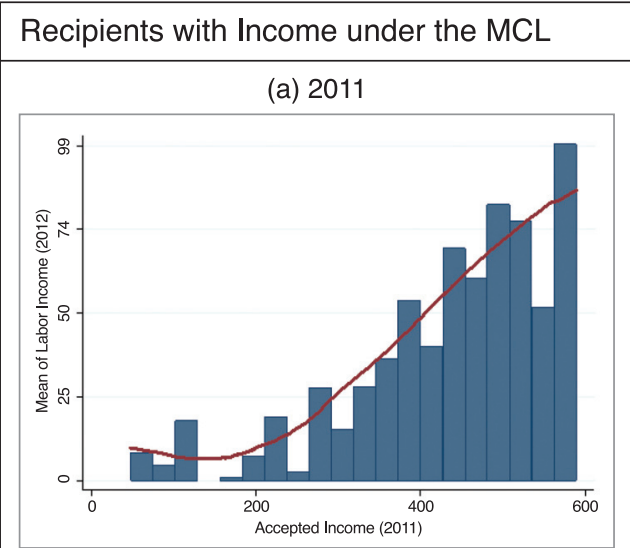

Mean $=25.44$

Nonrecipients with Income under the MCL

(c) 2011

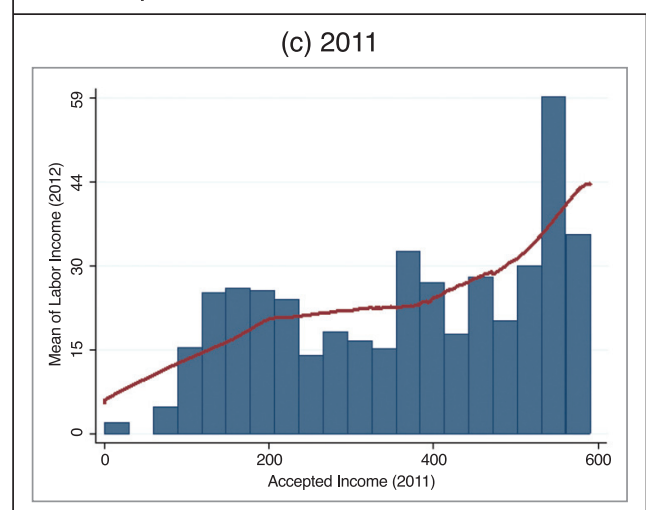

Mean $=25.40$ (b) 2012

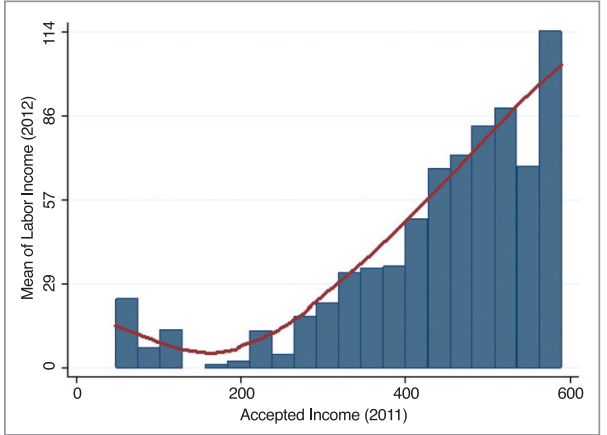

Mean $=25.41$

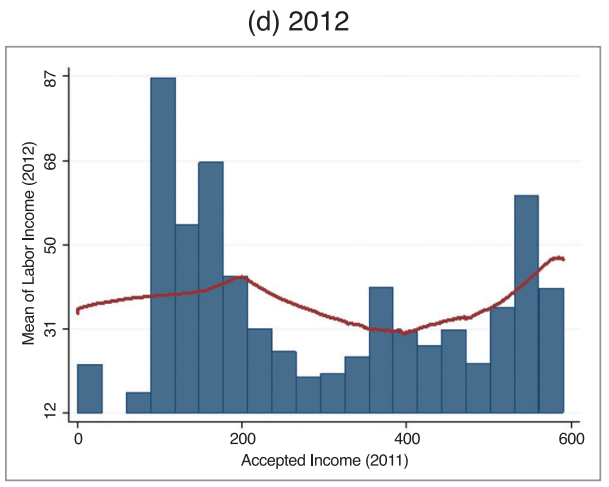

Mean $=34.09$ 
only the mean between two groups may not provide sufficient information about the labor supply because recipients and nonrecipients are systemically different from one another (no normal distribution), and therefore, relying on the mean effect without considering these differences may not be helpful for policy evaluation. Figure 3 shows that recipients with income under the MCL and nonrecipients with income under the MCL have very different distribution or abnormal distribution. More to the point, there is no information about the comparative group of nonrecipients whose income is above the MCL or cutoff point (\$590). As explained, the cutoff point can be a criterion for social policy evaluation. In the next section, we report on the RDD analysis we conducted to compensate for the insufficient information obtained from the DID evaluation.

\section{First RDD: Nonrecipients with Income under the MCL and Nonrecipients with Income above MCL}

This RDD evaluation was carried out in order to compare the RDD analysis of recipients with income above the MCL with that of nonrecipients with income above the MCL. The results of such an evaluation may reveal a counterfactual or potential outcome that could have been generated if the social policy had not been implemented.

We carried out a graphical analysis following Imbens and Lemieux (2008). First, we checked the histogram of average outcomes against assignment variables, as seen in figure $4 .{ }^{8}$ Second, we examined the continuity of covariates at the cutoff point and found smoothness between 0.25 and 0.5 in bandwidth. Figure 4 reveals that there appears to be no difference at the cutoff point in the number of days worked and labor income earned between nonrecipients with income under the MCL and nonrecipients with income above the MCL.

Table 4 shows the outcomes examined statistically by nonparametric estimation confirming graphic analysis. For the nonparametric method, bandwidth is important but difficult to choose, as explained. We selected bandwidth according to the guidelines outlined of Imbens and Lemieux (2008): first, we checked the robustness of estimations using bandwidths half and double the size provided by the Imbens-Kalyanaraman optimal bandwidth, and second, we balanced the minimized mean square error and smaller bandwidth. According to table 4, there is no difference between the two groups in each bandwidth $(1.7,3.5,6.9)$ with respect to number of working days, and labor income is likewise the same in each bandwidth $(1.9,3.8,7.6) .{ }^{9}$ These results,

8. Figure 4 shows local linear smooth plots and lines instead of a histogram, using 600 in bandwidth. 
Figure 4. Graphic for Nonparametric Estimation (Nonrecipients with Income under the MCL and Nonrecipients with Income above the $\mathrm{MCL}$ )

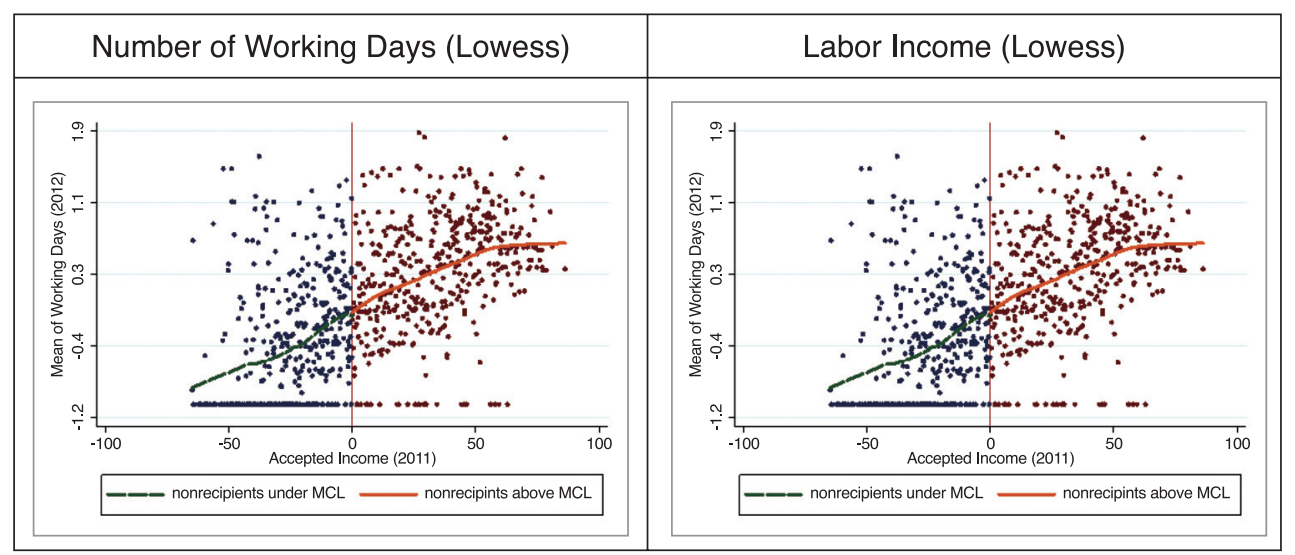

Table 4. Nonparametric Estimation (Nonrecipients with Income under and Nonrecipients with Income above MCL)

\begin{tabular}{c|c|c|c|c|c|c}
\hline & \multicolumn{3}{|c|}{ Working Days } & \multicolumn{3}{c}{ Labor Income } \\
\hline Bandwidth & 1.7 & 3.5 & 6.9 & 1.9 & 3.8 & 7.6 \\
\hline Coef. & .34 & .29 & .17 & .02 & .17 & .16 \\
$($ S.E.) & $(.52)$ & $(.32)$ & $(.22)$ & $(.47)$ & $(.28)$ & $(.19)$ \\
\hline
\end{tabular}

* Significant at $5 \%$. Robust standard errors in parentheses.

${ }^{* *}$ This study uses the rectangular kernel function for nonparametric estimation. Nonparametric estimations have bootstrapped standard errors (500 repetitions).

however, demonstrate only the local average treatment effect (LATE) of observations close to the cutoff point and not of the whole sample. Therefore, we should rely on parametric estimation.

According to Trochim (1984) and Wong et al. (2008), when a semiparametric estimation is conducted after a parametric estimation, it determines whether the linear interaction model is a fitting one in terms of the number of working days and labor income. For sensitivity analysis, this study reports the results of quadratic interaction and cubic interaction estimation together. Table 5 indicates that nonrecipients with income above the MCL worked more days than nonrecipients with income under the MCL (see the value (.07) of the coefficient $\delta$, which is the difference in the y-intercepts

9. Estimation results of less than 1.7 bandwidth show the same results for both number of days worked and labor income earned. 
Table 5. Semiparametric Estimation (Nonrecipients with Income under the MCL and Nonrecipients with Income above MCL)

\begin{tabular}{l|c|c|c|c|c|c}
\hline \multirow{2}{*}{ Model } & \multicolumn{3}{|c|}{ Number of Working Days } & \multicolumn{3}{c}{ Labor Income } \\
\cline { 2 - 7 } & $\begin{array}{c}\text { Linear } \\
\text { interaction }\end{array}$ & $\begin{array}{c}\text { Quadratic } \\
\text { interaction }\end{array}$ & $\begin{array}{c}\text { Cubic } \\
\text { interaction }\end{array}$ & $\begin{array}{c}\text { Linear } \\
\text { interaction }\end{array}$ & $\begin{array}{c}\text { Quadratic } \\
\text { interaction }\end{array}$ & $\begin{array}{c}\text { Cubic } \\
\text { interaction }\end{array}$ \\
\cline { 2 - 7 } & Coef. (S.E.) & Coef. (S.E.) & Coef. (S.E.) & Coef. (S.E.) & Coef. (S.E.) & Coef. (S.E.) \\
\hline$\delta D$ & $.07(.04)$ & $.02(.05)$ & $.11(.07)$ & $.06(.04)$ & $.04(.05)$ & $.04(.07)$ \\
\hline$\beta_{1} A A l$ & $.00(.00)^{*}$ & $.01(.00)$ & $-.01(.01)$ & $.01(.00)^{*}$ & $.01(.00)$ & $.01(.01)$ \\
\hline$\gamma_{1} D * A A l$ & $-.00(.00)$ & $-.00(.00)$ & $-.01(.01)$ & $.01(.00)^{*}$ & $.01(.00)$ & $-.01(.01)$ \\
\hline cons & $.56(.16)^{*}$ & $.59(.16)^{*}$ & $.57(.16)^{*}$ & $1.35(.13)^{*}$ & $1.36(.13)^{*}$ & $1.41(.13)^{*}$ \\
\hline Covariance & yes & yes & yes & Yes & yes & yes \\
\hline Obs. & 2581 & 2581 & 2581 & 2581 & 2581 & 2581 \\
Prob > F & $666.72^{*}$ & 602.72 & 547.57 & $672.09^{*}$ & $608.48^{*}$ & $551.38^{*}$ \\
$R^{2}$ & .74 & .74 & .74 & .74 & .74 & .74 \\
\hline
\end{tabular}

Covariates: sex, age, education, work number, labor ability, job, region, asset, private transfer, public transfer

Figure 5. Graphic for Parametric Estimation (Nonrecipients with Income under the MCL and Nonrecipients with Income above MCL)

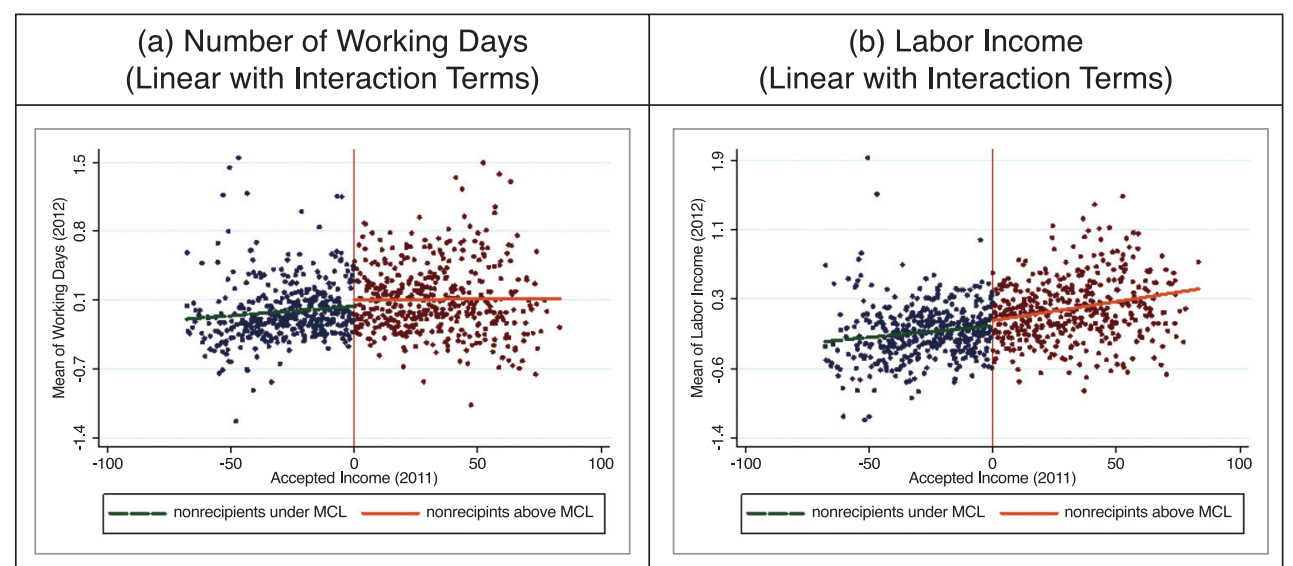

Covariates: sex, age, education, work number, labor ability, job, region, asset, private transfer, public transfer These graphics illustrate the effect of the NBLS program on the number of days worked by nonrecipients as well as their labor income with covariates kept constant.

at the cutoff point between the two groups). However, this is not significant in the linear interaction model. The quadratic interaction (.02) and cubic interaction (.11) models demonstrate similar results. In addition, labor income estimation shows statistically insignificant dominance of nonrecipients with income above the MCL over nonre- 
cipients with income under the MCL in every model $(.06, .04, .04)$. In addition, the coefficient $\gamma_{1}$, indicating the difference in the slopes of the regression line between the two groups, is not significant, meaning that the systemic difference in nonrecipients with income above the MCL in terms of the number of working days and labor income is continuous for nonrecipients with income under the MCL. Figure 5 shows no noticeable differences in the y-intercept or the slopes of the regression line between the two groups in terms of the number of working days and labor income, which confirms the results of table 5 .

The results of nonparametric, semiparametric, and graphical estimation show that there are no differences in number of days worked and labor income earned by nonrecipients with income under the MCL and nonrecipients with income above the MCL. These outcomes indicate the counterfactual effect of the NBLS's welfare-to-work program.

\section{Second RDD: Recipients with Income under the MCL and Nonrecipients with Income above the MCL}

This study finds that a DID evaluation does not provide sufficient information for assessing policy success. The RDD analysis of nonrecipients with income under the MCL and nonrecipients with income above the MCL revealed that there is no difference in the number of days worked and labor income earned by the two groups before the implementation of the NBLS program. Based on these results, we conducted a second RDD analysis of recipients with income under the MCL and of nonrecipients with income above the MCL.

First, we examined the continuity of covariates at the cutoff point, finding smoothness between 0.25 and 0.5 in bandwidth. However, we did not carry out an assignment density test because the proportion of ineligible recipients was about $1 \%$ in 2009, according to the Ministry of Health and Welfare (2013), and because the dataset of the KWPS comprises panel data compiled annually by investigators. ${ }^{10}$ We assumed, therefore, that the density of assignment is smoothing at the cutoff point. Second, the local linear smooth plot and lines of average outcomes against assignment variables, as can be seen in Figure 6, report the possibility of a decided difference at the cutoff point in both the number of days worked and labor income earned between recipients with income under the MCL and by nonrecipients with income above the MCL.

Table 6 shows that all results have statistical significance. The coefficients of the

10. Some people self-select to benefit from the program by fitting their situation to the requirements; thus, a test of assignment density is needed to prevent bias in the estimation results. 
Figure 6. Graphic for Nonparametric Estimation (Recipients with Income under the MCL and Nonrecipients with Income above the MCL)

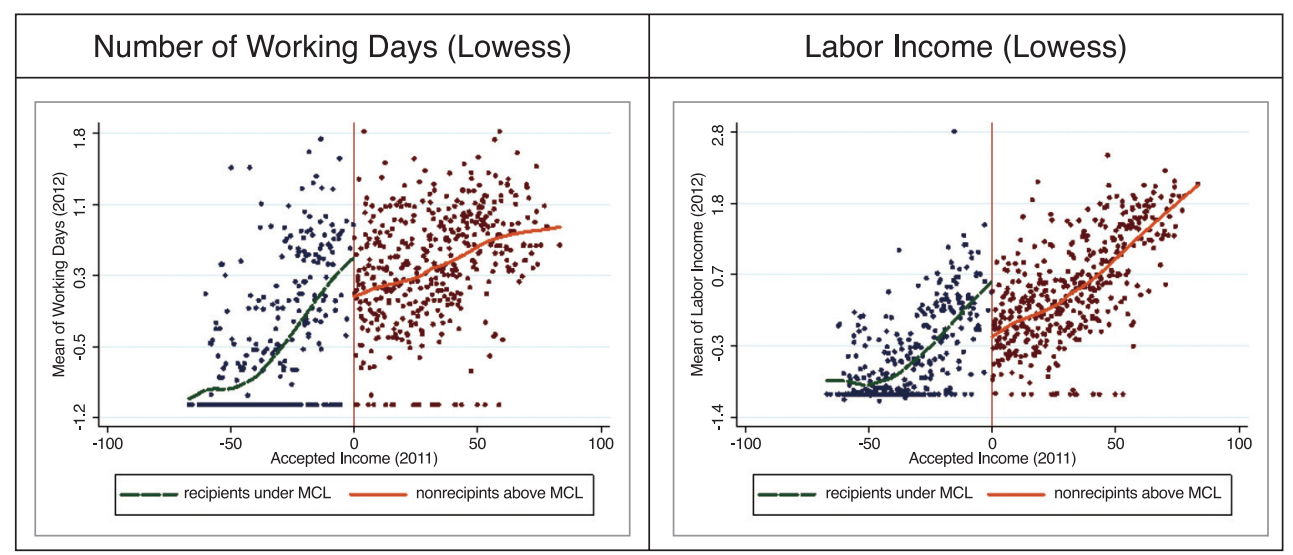

Table 6. Nonparametric Estimation (Recipients with Income under the MCL and Nonrecipients with Income above the MCL)

\begin{tabular}{c|c|c|c|c|c|c}
\hline & \multicolumn{3}{|c|}{ Working Days } & \multicolumn{3}{c}{ Labor Income } \\
\hline Bandwidth & 1.6 & 3.3 & 6.7 & 1.6 & 3.1 & 6.3 \\
\hline Coef. & -.68 & -.77 & -.63 & -.67 & -.57 & -.58 \\
(S.E.) & $(.31)^{\star}$ & $(.24)^{\star}$ & $(.24)^{\star}$ & $(.27)^{\star}$ & $(.20)^{\star}$ & $(.18)^{\star}$ \\
\hline
\end{tabular}

* Significant at $5 \%$

** This study uses the rectangular kernel function for nonparametric estimation. Nonparametric estimations have bootstrapped standard errors (500 repetitions).

number of working days are -.68, -.77, and -.63 in each bandwidth (1.6, 3.3, and 6.7) and those of labor income are -.67, -.57, and -.58 in each bandwidth (1.6, 3.1, and 6.3), which indicates that recipients with income under the MCL outstrip nonrecipients with income above the MCL. ${ }^{11}$

We then undertook a semiparametric estimation in order to find the effects that influence the whole sample of recipients rather than just the samples close to the cutoff point. From parametric estimation, we know that a quadratic interaction model could be more fitted with respect to number of working days and labor income. As Table 7 shows, the coefficient $\delta$ values in working days are -.10, -.23, and -.14 in the linear interaction, quadratic interaction, and cubic interaction models, respectively. The coef-

11. Results of bandwidth less than 1.6 also show recipients' superiority, but no statistical significance. 
Table 7. Semiparametric Estimation (Recipients with Income under the MCL and Nonrecipients with Income above the MCL)

\begin{tabular}{l|c|c|c|c|c|c}
\hline \multirow{4}{*}{ Model } & \multicolumn{3}{|c|}{ Number of Working Days } & \multicolumn{3}{c}{ Labor Income } \\
\cline { 2 - 7 } & $\begin{array}{c}\text { Linear } \\
\text { interaction }\end{array}$ & $\begin{array}{c}\text { Quadratic } \\
\text { interaction }\end{array}$ & $\begin{array}{c}\text { Cubic } \\
\text { interaction }\end{array}$ & $\begin{array}{c}\text { Linear } \\
\text { interaction }\end{array}$ & $\begin{array}{c}\text { Quadratic } \\
\text { interaction }\end{array}$ & $\begin{array}{c}\text { Cubic } \\
\text { interaction }\end{array}$ \\
\cline { 2 - 7 } & Coef. (S.E.) & Coef. (S.E.) & Coef. (S.E.) & Coef. (S.E.) & Coef. (S.E.) & Coef. (S.E.) \\
\hline$\delta D$ & $-.10(.06)^{\star}$ & $-.23(.10)^{\star}$ & $-.14(.12)^{\star}$ & $-.20(.06)^{\star}$ & $-.21(.10)^{\star}$ & $-.24(.14)^{\star}$ \\
\hline$\beta_{1} A A I$ & $.02(.00)^{\star}$ & $.02(.01)^{\star}$ & $.02(.01)$ & $.02(.00)^{\star}$ & $.02(.01)^{\star}$ & $.03(.01)$ \\
\hline$\gamma_{1} D * A A I$ & $-.01(.01)^{\star}$ & $-.02(.01)^{\star}$ & $-.02(.01)^{\star}$ & $-.01(.00)^{\star}$ & $-.01(.01)^{\star}$ & $-.02(.01)$ \\
\hline cons & $.83(.124)^{\star}$ & $.93(.16)^{\star}$ & $.90(.17)^{\star}$ & $1.54(.13)^{\star}$ & $1.55(.15)^{\star}$ & $1.62(.17)$ \\
\hline Covariance & yes & yes & yes & Yes & yes & yes \\
\hline Obs. & 2075 & 2075 & 2075 & 2075 & 2075 & 2075 \\
Prob > F & $340.80^{*}$ & $564.32^{*}$ & $513.58^{*}$ & $519.19^{\star}$ & $466.83^{*}$ & $426.84^{*}$ \\
$R^{2}$ & .74 & .74 & .74 & .74 & .74 & .74 \\
\hline
\end{tabular}

${ }^{*} \mathrm{p}<.05$, Robust standard errors in parentheses.

Figure 7. Graphic for Parametric Estimation (Recipients with Income under the MCL and Nonrecipients with Income above the $\mathrm{MCL}$ )

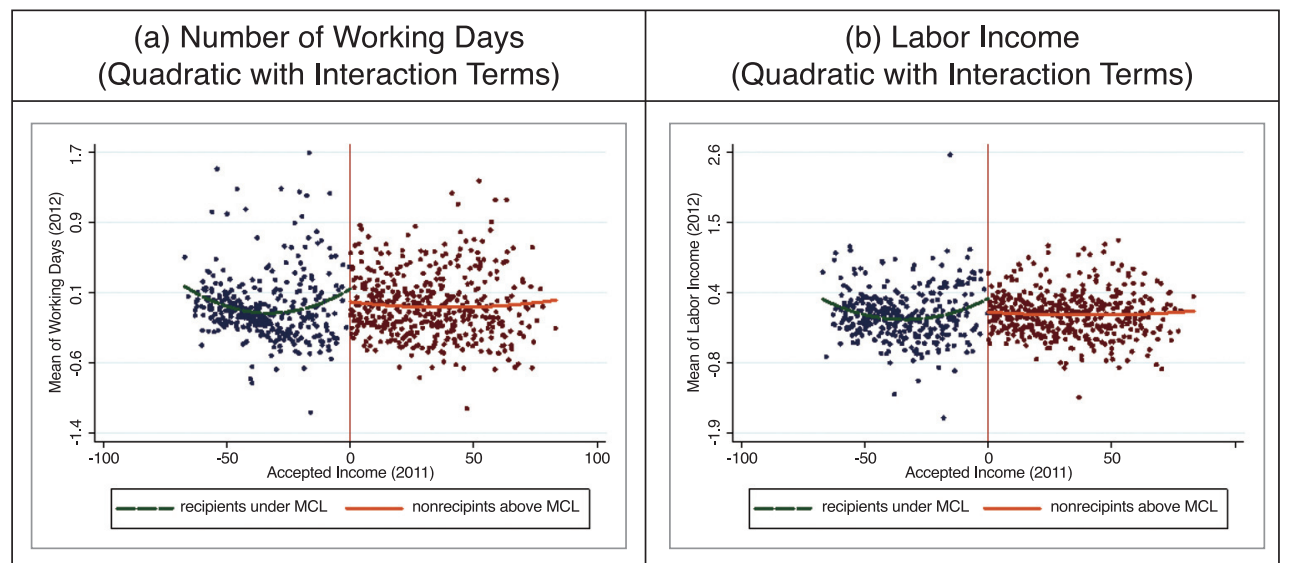

Covariates: sex, age, education, work number, labor ability, job, region, asset, private transfer, public transfer These graphics illustrate the NBLS effect on the number of days worked and labor income earned with covariates kept constant.

ficient $\delta$ values in labor income are -.20, -.21, and -.24 in each model, respectively, and the p-values of all $\delta$ are less than .05 . These results support those of nonparametric estimation.

Figure 7 shows the effect of NBLS on the number of days worked and labor 
income earned without the effects of covariates mixed in, highlighting the difference between the two groups at the cutoff point, namely, that recipients supply more labor. Furthermore, the line of quadratic fit shows that the NBLS program has a greater effect on households suffering from severe poverty that are close to the cutoff point in terms of labor supply.

Comparing nonparametric and semiparametric estimations, it appears that the NBLS welfare-to-work program is successful in helping recipients become part of the labor force, and this is true for the whole sample set and not just the samples near the cutoff point. Nevertheless, as can be seen in Figure 6, it is obvious that nonrecipients with income above the MCL outstrip recipients in terms of labor supply, which could be interpreted as a partial policy success. However, many recipients are limited in increasing their labor supply because the conditions for the labor supply of recipients are inferior to those of nonrecipients. For example, the portion the recipients who cannot work at all, those who can only undertake only household chores, and those earning money only at home is $50.76 \%$ of recipients with income under the MCL compared to $20.01 \%$ of nonrecipients with income above the MCL (see appendix table 2). Therefore, it may be impossible to determine final and long-term policy effects in terms of the absolute quantity of labor supply. ${ }^{12}$ On the other hand, considering that in figure 7 , the number of days worked and the labor income earned by recipients with covariates kept constant are not low compared to nonrecipients with income above the MCL, it seems that NBLS program may be help increase their labor supply. In addition, the impact of the NBLS program on disposable income and consumption expenditure is positive; in other words, nonparametric and semiparametric estimations reveal higher disposable income and consumption among recipients with income below the MCL than among nonrecipients with income above the MCL at the cutoff point (see appendix table 3 and figure 1).

\section{CONCLUSION}

We have argued for the relative suitability of using RDD rather than DID to evaluate whether a given social policy has been successful and applied RDD to the NBLS welfare-to-work program in Korea as a case study. It is not appropriate to assess the success of a given social program by the average effect produced by using DID because there are systematic and prior differences between experiment and control

12. For a review of the limited effectiveness of welfare-to-work program for sick and disabled people, see Weston (2012). 
groups before social assistance, and thus, the criteria for evaluating policy performance are ambiguous. In comparison, RDD can reveal more precise effects because it estimates the policy effect by differences of the y-intercept at the cutoff point that divides the experiment and control groups, and it uses the cutoff point (e.g., MCL) as a minimum criterion to determine success. Furthermore, the graphic analysis of an RDD approach can uncover systematic differences of policy effects through the experiment group whereas DID can find only the mean effects.

We have investigated how the Korean NBLS program affects labor supply. First, our DID estimation demonstrated that nonrecipients with income under the MCL worked more days and earned more labor income than recipients, which would appear to signal the failure of the welfare-to-work program. However, these results did not provide any comparative information on nonrecipients with income above the MCL, information that is needed to assess real effects. So we then carried out an RDD analysis of nonrecipients with income under the MCL and nonrecipients with income above the MCL to determine counterfactual outcomes; this analysis revealed no difference in the number of days worked, labor outcomes, or in the slopes of the regression line. Last, we conducted an RDD analysis of recipients with income below the MCL and nonrecipients with income above the MCL in order to ascertain the real effect of the welfare-to-work program after policy implementation, the result of which shows that recipients with income below the MCL supplied more labor than nonrecipients with income above the MCL. Moreover, the effects of the policy, as demonstrated by graphic analysis, were greater on the destitute. It is not likely, however, that recipients with income under the MCL surpassed nonrecipients with income above the MCL in terms of absolute labor supply. We believe that the result showing that recipients with income under the MCL supplied more labor arises from the fact that welfare beneficiaries often have weak labor skills because of disability, disease, and so on. However, when other influencing factors are kept constant, the labor supply of these welfare beneficiaries is still estimated to be higher than that of nonrecipients with income above the MCL. Consequently, the RDD evaluation demonstrates that the NBLS welfare-towork program has helped recipients join the labor market, which contrasts with what the DID analysis suggests.

We have suggested adopting a new and more precise method for measuring the effects of social policy; however, this method is limited by data integrity. Even though we did use two types of data were to compensate for this, future studies will be able to validate the results of this study with better data and more sophisticated methods. 
Appendix Table 1. Basic Statistics (Nonrecipients with Income under the MCL and Nonrecipients with Income above the $\mathrm{MCL}$ )

\begin{tabular}{|c|c|c|c|}
\hline \multirow[b]{2}{*}{ Variable } & \multicolumn{2}{|c|}{ Mean } & \multirow{2}{*}{$\begin{array}{c}\text { t-test } \\
T\end{array}$} \\
\hline & $\begin{array}{l}\text { Nonrecipients with } \\
\text { Income under the MCL } \\
(D=1)\end{array}$ & $\begin{array}{l}\text { Nonrecipients with } \\
\text { Income above the MCL } \\
(D=0)\end{array}$ & \\
\hline Age ( in Years) & 71.35 & 61.18 & $19.03^{*}$ \\
\hline Female (\%) & .56 & .30 & $13.32^{*}$ \\
\hline Education (in Years) & 5.76 & 8.83 & $-18.33^{*}$ \\
\hline Labor Ability (Weak \%) & .42 & .19 & $12.85^{\star}$ \\
\hline Labor Ability (Strong \%) & .56 & .80 & -13.23 \\
\hline Number of Family Members & 1.24 & 1.50 & -18.76 \\
\hline $\begin{array}{l}\text { Number of Household } \\
\text { Members Employed }\end{array}$ & .56 & .95 & -17.39 \\
\hline Region (City \%) & .34 & .39 & -2.77 \\
\hline Region (Rural \%) & .34 & .25 & $5.08^{*}$ \\
\hline Job (Irregularly Employed \%) & .15 & .24 & $-5.53^{\star}$ \\
\hline Job (Self-Employed \%) & .18 & .25 & -3.80 \\
\hline Job (Unemployed (\%) & .65 & .37 & $14.26^{\star}$ \\
\hline Number of Working Days & 6.54 & 12.99 & -18.96 \\
\hline Labor Income & 32.93 & 81.73 & $-24.46^{\star}$ \\
\hline Assets & 7.19 & 10.44 & -4.82 \\
\hline Private Transfer & 54.59 & 48.19 & $6.21^{*}$ \\
\hline Public Transfer & 35.37 & 38.43 & $-3.63^{\star}$ \\
\hline Disposable Income & 84.51 & 118.15 & $-27.53^{\star}$ \\
\hline Consumption & 88.83 & 121.20 & $-25.18^{*}$ \\
\hline Observations & 1227 & 1354 & \\
\hline
\end{tabular}


Appendix Table 2. Basic Statistics (Recipients with Income under the MCL and Nonrecipients with Income above the $\mathrm{MCL}$ )

\begin{tabular}{|c|c|c|c|}
\hline \multirow[b]{2}{*}{ Variable } & \multicolumn{2}{|c|}{ Mean } & \multirow{2}{*}{$\begin{array}{c}\text { t-test } \\
T\end{array}$} \\
\hline & $\begin{array}{l}\text { Nonrecipients with } \\
\text { Income under the MCL } \\
(D=1)\end{array}$ & $\begin{array}{l}\text { Nonrecipients with } \\
\text { Income above the MCL } \\
(D=0)\end{array}$ & \\
\hline Age (in Years) & 63.29 & 61.18 & $3.13^{*}$ \\
\hline Female (\%) & .57 & .30 & $11.97^{\star}$ \\
\hline Education (in Years) & 7.06 & 8.83 & $-8.97^{\star}$ \\
\hline Labor Ability (Weak \%) & .48 & .19 & $13.59^{*}$ \\
\hline Labor Ability (Strong \%) & .49 & .80 & $-14.46^{*}$ \\
\hline Number of Family Members & 1.34 & 1.49 & $-9.00^{*}$ \\
\hline $\begin{array}{l}\text { Number of Household } \\
\text { Members Employed }\end{array}$ & .44 & .95 & $-19.82^{*}$ \\
\hline Region (City \%) & .31 & .39 & $-3.67^{\star}$ \\
\hline Region (Rural \%) & .18 & .25 & $-3.66^{\star}$ \\
\hline Job (Irregularly Employed \%) & .15 & .24 & $-4.86^{\star}$ \\
\hline Job (Self-Employed \%) & .06 & .25 & $-10.58^{*}$ \\
\hline Job (Unemployed \%) & .78 & .37 & $17.86^{\star}$ \\
\hline Number of Working Days & 4.46 & 12.99 & $-21.91^{*}$ \\
\hline Labor Income & 27.98 & 81.73 & $-21.83^{*}$ \\
\hline Assets & 1.20 & 10.44 & $-12.85^{\star}$ \\
\hline Private Transfer & 31.57 & 48.17 & $-13.79^{\star}$ \\
\hline Public Transfer & 68.65 & 38.43 & $28.35^{\star}$ \\
\hline Disposable Income & 91.59 & 118.15 & $-17.29^{*}$ \\
\hline Consumption & 92.42 & 121.20 & $-25.66^{*}$ \\
\hline Observations & 721 & 1354 & \\
\hline
\end{tabular}


Appendix Table 3. Nonparametric Estimation (Recipients with Income under MCL and Nonrecipients with Income above MCL)

\begin{tabular}{c|c|c|c|c|c|c}
\hline & \multicolumn{3}{|c|}{ Disposable Income } & \multicolumn{3}{c}{ Consumption Expenditure } \\
\hline Bandwidth & 1.6 & 3.2 & 6.4 & 1.6 & 3.2 & 6.5 \\
\hline Coef. & -.85 & -.61 & -1.16 & -1.73 & -1.64 & -1.66 \\
(S.E.) & $(.20)^{\star}$ & $(.24)^{\star}$ & $(.21)^{\star}$ & $(.24)^{*}$ & $(.20)^{\star}$ & $(.20)^{\star}$ \\
\hline
\end{tabular}

* Significant at $5 \%$. Robust standard errors in parentheses.

** This study uses the rectangular kernel function for nonparametric estimation. Nonparametric estimations have bootstrapped standard errors (500 repetitions).

Appendix Figure 1. Graphic for Parametric Estimation (Recipients with Income under the MCL and Nonrecipients with Income above the MCL)

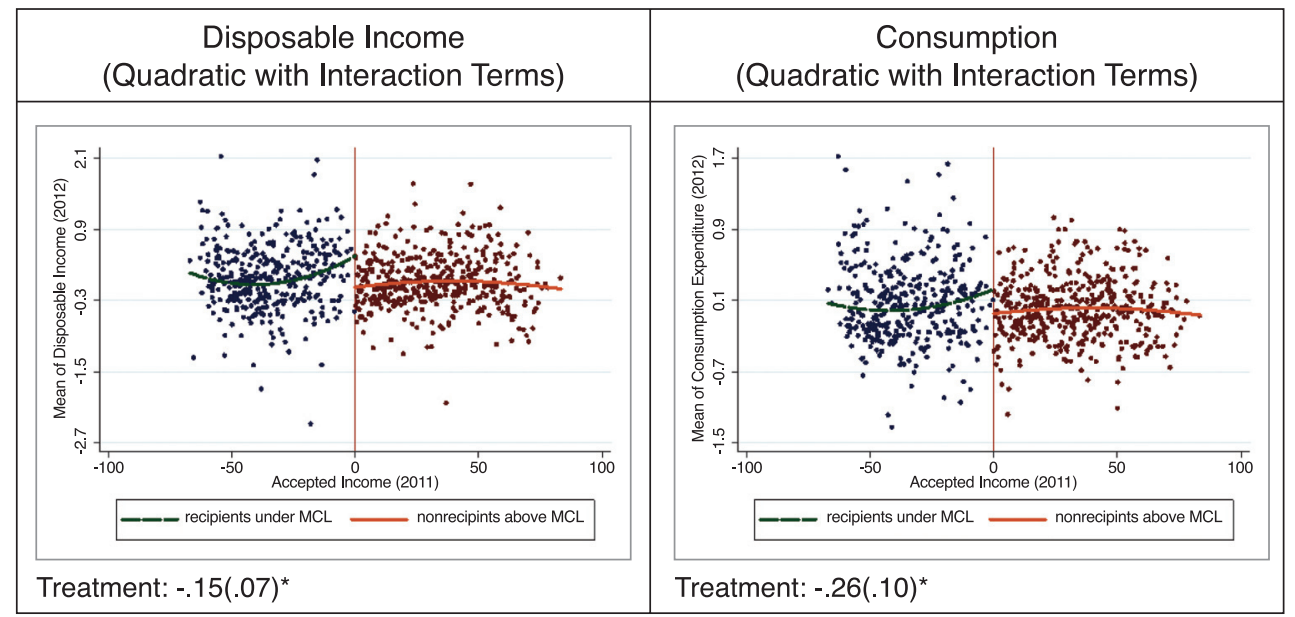

* Significant at 5\%. Robust standard errors in parentheses.

${ }^{* *}$ Covariates: sex, age, education, work number, labor ability, job, region, asset, private transfer, public transfer

*** These graphics illustrate the NBLS effect on the number of days worked and labor income earned with covariates kept constant. 


\section{REFERENCES}

Angrist, J. D., \& Lavy, V. 1999. Using Maimonides' rule to estimate the effect of class size on scholastic achievement. Quarterly Journal of Economics, 114(2): 533575.

Angrist, J. D., \& Pischke, J.-S. 2008. Mostly harmless econometrics: An empiricist's companion. Princeton, NJ: Princeton University Press.

Atkinson, A. B., Rainwater, L., \& Smeeding, T. M. 1995. Income distribution in OECD countries: Evidence from the Luxembourg Income Study. Paris: OECD.

Bavier, R. 2001. Welfare reform data from the Survey of Income and Program Participation. Monthly Labor Review, July, 13.

Black, D., Galdo, J., \& Smith, J. A. 2005. Evaluating the regression discontinuity design using experimental data. Unpublished manuscript.

Bloom, H. S., Hill, C. J., \& Riccio, J. A. 2003. Linking program implementation and effectiveness: Lessons from a pooled sample of welfare-to-work experiments. Journal of Policy Analysis and Management, 22(4): 551-575.

Cancian, M., Haveman, R. H., Meyer, D. R., \& Wolfe, B. 2002. Before and after TANF: The economic well-being of women leaving welfare. Social Service Review, 76(4): 603-641.

Cheng, T. 2010. Financial self-sufficiency or return to welfare? A longitudinal study of mothers among the working poor. International Journal of Social Welfare, 19(2): 162-172.

Danziger, S., Heflin, C. M., Corcoran, M. E., Oltmans, E., \& Wang, H. C. 2002. Does it pay to move from welfare to work? Journal of Policy Analysis and Management, 21(4): 671-692.

Eardley, T., Bradshaw, J., Ditch, J., \& Gough, I. 1996. Social assistance in OECD countries Synthesis report. Department of Social Security Research Report No. 46. London: HMSO.

Ellwood, D. T. 2000. Anti-poverty policy for families in the next century: From welfare to work - and worries. Journal of Economic Perspectives, 187-198.

Fan, J., \& Gijbels, I. 1996. Local polynomial modelling and its applications. Monographs on statistics and applied probability, vol. 66. Boca Raton, FL: CRC Press.

Gilbert, N. 2009. US welfare reform: Rewriting the social contract. Journal of Social Policy, 38(3): 383-399.

Goldberger, A. S. 2008. Selection bias in evaluating treatment effects: Some formal illustrations. Advances in Econometrics, 21: 1-31.

Grogger, J. 2003. The effects of time limits, the EITC, and other policy changes on welfare use, work, and income among female-headed families. Review of Economics 
and Statistics, 85(2): 394-408.

Gruber, J. 2000. Cash welfare as a consumption smoothing mechanism for divorced mothers. Journal of Public Economics, 75(2): 157-182.

Guo, S., \& Fraser, M. 2010. Propensity score analysis: Statistical methods and applications, vol. 12. Thousand Oaks, CA: Sage.

Hahn, J., Todd, P., \& Van der Klaauw, W. 2001. Identification and estimation of treatment effects with a regression-discontinuity design. Econometrica, 69(1): 201-209.

Heckman, J. J., \& Robb, R. 1985. Alternative methods for evaluating the impact of interventions: An overview. Journal of Econometrics, 30(1): 239-267.

Imbens, G. W., \& Kalyanaraman, K. 2012. Optimal bandwidth choice for the regression discontinuity estimator. Review of Economic Studies, 79(3): 933-959.

Imbens, G. W., \& Lemieux, T. 2008. Regression discontinuity designs: A guide to practice. Journal of Econometrics, 142(2): 615-635.

Kim, E. S. 2008. National Basic Livelihood Security and labor supply. Paper presented at the Korea Labor Panel Conference, 2002, Seoul, Korea.

Lemieux, T., \& Milligan, K. 2008. Incentive effects of social assistance: A regression discontinuity approach. Journal of Econometrics, 142(2): 807-828.

Lightman, E., Mitchell, A., \& Herd, D. 2010. Cycling off and on welfare in Canada. Journal of Social Policy, 39(4): 523-542.

Ludwig, J., \& Miller, D. L. 2007. Does Head Start improve children's life chances? Evidence from a regression discontinuity design. Quarterly Journal of Economics, 122(1): 159-208.

Meyer, B. D., \& Rosenbaum, D. T. 2000. Making single mothers work: Recent tax and welfare policy and its effects. No. w7491. Ann Arbor: University of Michigan, National Bureau of Economic Research.

Ministry of Health and Welfare. 2001. Reform of the national basic livelihood security system. Seoul: Ministry of Health and Welfare.

Ministry of Health and Welfare. 2013. Report on illegal recipience of national basic livelihood security. Seoul: Ministry of Health and Welfare.

OECD. 2008. Growing unequal? Income distribution and poverty in OECD Countries. Paris: OECD.

OECD. 2011. Divided we stand: Why inequality keeps rising. Paris: OECD.

Page, M. E., \& Stevens, A. H. 2005. Understanding racial differences in the economic costs of growing up in a single-parent family. Demography, 42(1): 75-90.

Park, S. H., \& Kim, T.-I. 2011. Impact of National Basic Livelihood System on labor supply and performance. Korean Policy Studies Review, 20(4): 277-307.

Rønsen, M., \& Skarðhamar, T. 2009. Do welfare-to-work initiatives work? Evidence from an activation programme targeted at social assistance recipients in Norway. 
Journal of European Social Policy, 19(1): 61-77.

Rafferty, A., \& Wiggan, J. 2011. Choice and welfare reform: Lone parents' decision making around paid work and family life. Journal of Social Policy, 40(2): 275-293.

Rosen, H. S. 2004. Public finance. In C.K. Rowley \& F. Schneider (eds.), The encyclopedia of public choice, vol. 1 (pp. 252-262). Dordrecht: Kluwer.

Rosenbaum, P. R., \& Rubin, D. B. 1983. Assessing sensitivity to an unobserved binary covariate in an observational study with binary outcome. Journal of the Royal Statistical Society, Series B (Methodological): 212-218.

Schoeni, R. F., \& Blank, R. M. 2000. What has welfare reform accomplished? Impacts on welfare participation, employment, income, poverty, and family structure. No. w7627. Ann Arbor: University of Michigan National Bureau of Economic Research.

Schwartz, S., \& Zabel, J. 2008. The employment impacts of active labour market policy: The case of SSP Plus. Canadian Public Policy, 34(3): 321-344.

Shadish, W. R., Galindo, R., Wong, V. C., Steiner, P. M., \& Cook, T. D. 2011. A randomized experiment comparing random and cutoff-based assignment. Psychological Methods, 16(2): 179.

Thistlethwaite, D. L., \& Campbell, D. T. 1960. Regression-discontinuity analysis: An alternative to the ex post facto experiment. Journal of Educational Psychology, 51(6): 309.

Trochim, W. M. 1984. Research design for program evaluation: The regressiondiscontinuity approach. Newbury Park, CA: Sage.

Van der Klaauw, W. 2002. Estimating the effect of financial aid offers on college enrollment: A regression-discontinuity approach. International Economic Review, 43(4): 1249-1287.

Waddan, A. 2003. Redesigning the welfare contract in theory and practice: Just what is going on in the USA? Journal of Social Policy, 32(1): 19-35.

Weston, K. 2012. Debating conditionality for disability benefits recipients and welfare reform: Research evidence from pathways to work. Local Economy, 27(5-6): 514-528.

Whitworth, A. 2013. Lone parents and welfare-to-work in England: A spatial analysis of outcomes and drivers. Social Policy and Administration, 47(7): 826-845.

Wong, V. C., Cook, T. D., Barnett, W. S., \& Jung, K. 2008. An effectiveness-based evaluation of five state pre-kindergarten programs. Journal of Policy Analysis and Management, 27(1): 122-154. 